Iranian Quarterly Journal of Breast Disease 2018; 11(2):36.

\title{
Relationship of Patience and Self- Compassion with Depression in Patients with Breast Cancer
}

\author{
Sharifi Saki Sh: Psychology, Payam Noor University, Tehran, Iran \\ Alipour A: Psychology, Payam Noor University, Tehran, Iran \\ AghaYousefi AR: Associate of Psychology, Payam Noor University Tehran, Iran \\ Mohammadi MR: psychiatry\& psychology Research Center, Tehran University of Medical Sciences, Tehran, \\ Iran \\ Ghobari Bonab B: Special Education Faculty of psychology\& Education, Tehran University Tehran, Iran \\ Anbiaee R: Radiation Oncologist, Shahid Beheshti University of Medical Science, Iran
}

Corresponding Author: Sheida Sharifi Saki, sheidasharifi1348@gmail.com

\begin{abstract}
Introduction: Breast cancer is one of the common malignant cancers in the world. Being informed about having the disease often causes mental distress and depression in patients. Studies show that the prevalence of depression in patients with breast cancer is $13 \%$ to $33 \%$. Therefore, the present study was conducted to determine the predictive factors for depression in patients with breast cancer. The researchers also aimed at studying the associations among compassion, patience, and depression in breast cancer patients.

Methods: This was a cross-sectional study. The study population included all the women with breast cancer referred to the chemotherapy and oncology departments in Mahdieh Clinical Center, Imam Khomeini Hospital, Firoozgar Hospital, and Pars Hospital in Tehran in 2017. A sample of 397 patients was selected based on the Cochran formula through availability sampling. Participants completed Beck's Depression Inventory (BDI), the patience questionnaire by Khormaei et al, and Neff's Self-compassion Scale. A multiple stepwise regression was performed to determine the role of patience and compassion in predicting depression, and the relationships among depression, compassion, and patience were explored by calculating the Pearson correlation coefficients. All analyses were performed using SPSS 24.
\end{abstract}

Results: No significant relationship was observed between depression and patience $(r=0.07, p>0.05)$, but there was a relationship between depression and transcendence $(r=0.08, p<0.05)$, patience $(r=0.11$, $\mathrm{p}<0.05)$, satisfaction $(\mathrm{r}=0.15, \mathrm{p}<0.01)$, and hesitation $(\mathrm{r}=-0.09, \mathrm{p}<0.05)$. In addition, correlation coefficients for depression and other components were obtained (overall compassion score: $r=0.11$, $\mathrm{p}<0.05$; self-kindness: $\mathrm{r}=0.31, \mathrm{p}<0.01$; self-judgment: $\mathrm{r}=0.24, \mathrm{p}<0.01$; mindfulness: $\mathrm{r}=0.27, \mathrm{p}<0.01$; and common humanity $(r=0.34, p<0.01)$. Self-kindness and common humanity accounted for $15 \%$ of the variance in depression in patients with cancer $(\mathrm{p}<0.01)$.

Conclusion: Patience enhances tolerance by developing resilience. On the other hand, self-compassion leads to higher emotional flexibility in dealing with cancer. Thus, it could be concluded that there is a relationship between self-compassion and depression in patients with breast cancer. Therefore, it is suggested that health professionals in hospitals should pay attention to enhancing patience and kindness in their interventions.

Keywords: Patience, Compassion, Depression, Breast Cancer 


\title{
بررسى رابطه صبر و شفقت به خود با افسردى در زنان مبتلا به سرطان يستان
}

\author{
شيدا شريفى ساكى ": كروه روانشناسى، دانشكاه بِيام نور، تهران، ايران

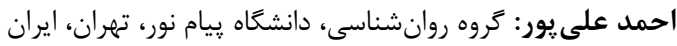

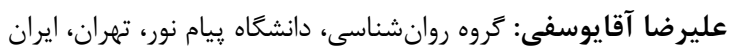

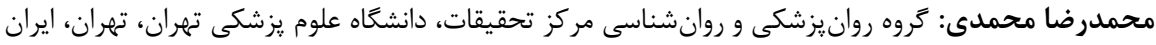

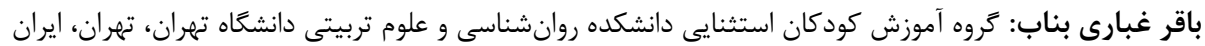

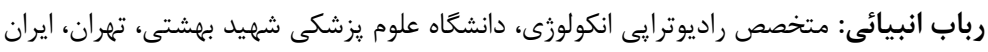

\section{جكيده}

مقدمه: سرطان يستان يكى از سرطانهاى بدخيم رايج در سراسر جهان است دريافت خبر آن اغلب باعث يريشانى روانى و شكل كيرى

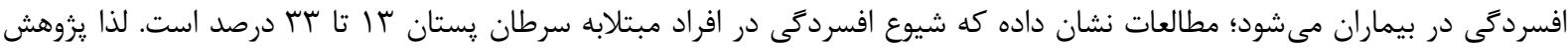

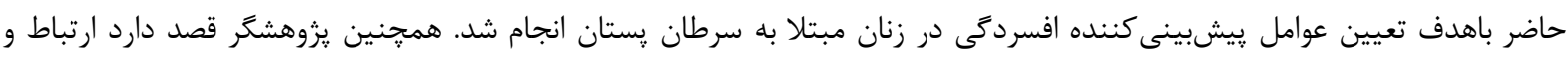

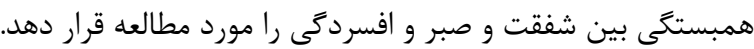

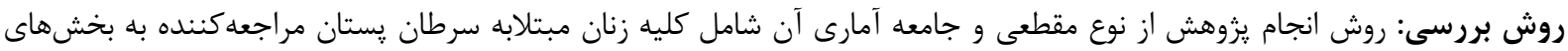

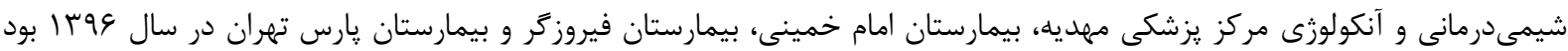

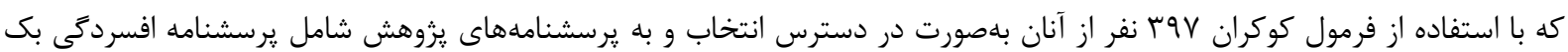

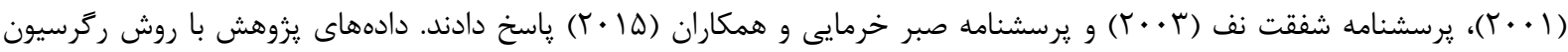

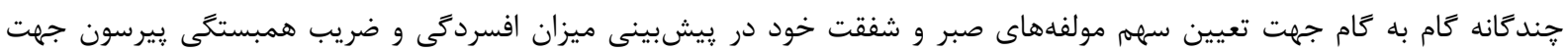

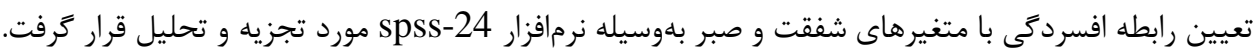

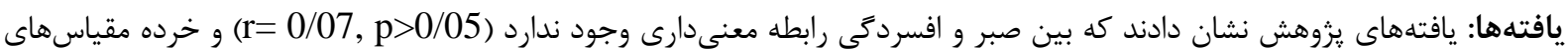

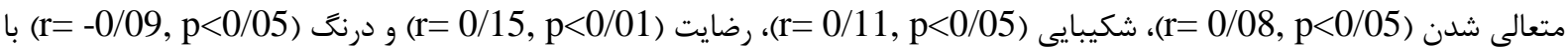

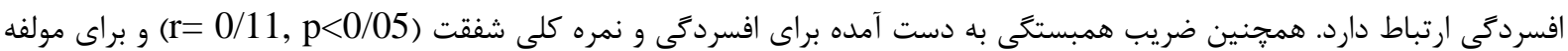

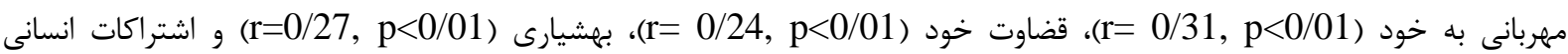

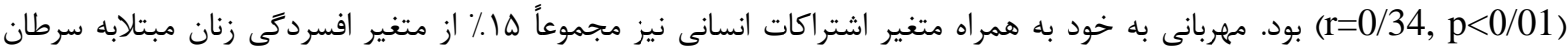

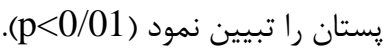

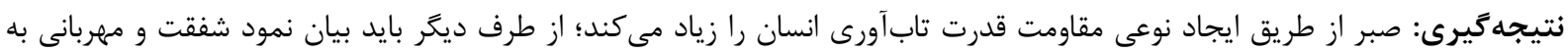

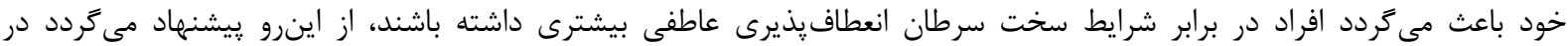

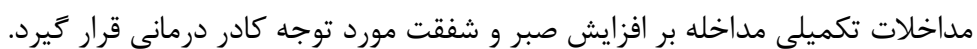

$$
\text { وازمهاى كليدى: صبر، شفقت، افسردىى، سرطان }
$$




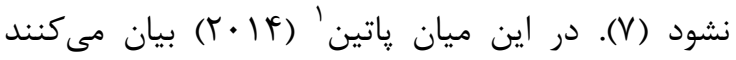

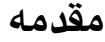
افرادى كه ميزان صبر بالاترى براى تحمل سختىها دارند، حمايت بيشترى از اطرافيان دريافت مى كنند و در انتظار

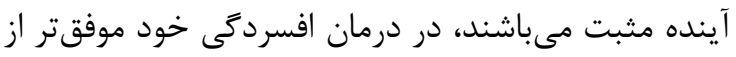

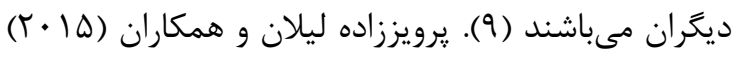

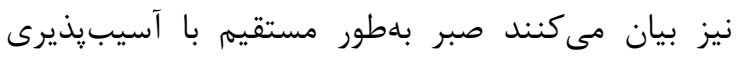

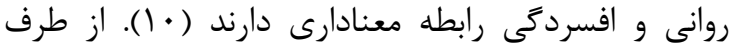

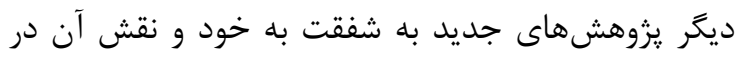
شكلىيرى سلامت روان و ويشكيرى در برابر اختلالات

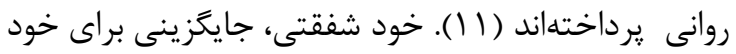

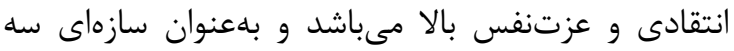
مولفهاى متشكل از مهربانى با خود در مقابل قضاوت كردن بان ونان

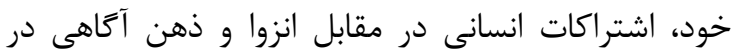

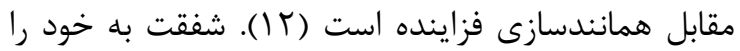
مى توان بهعنوان يك موضع مثبت نسبت به خود زمانى كه

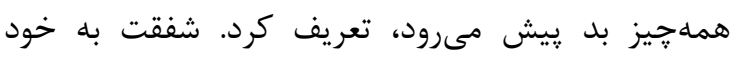
بهنوان يك صفت و يك عامل محافظ مؤثر براى يرورش

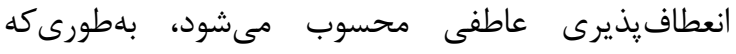

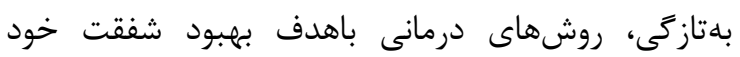

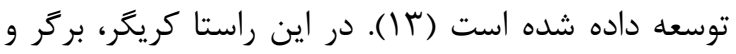

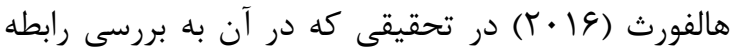

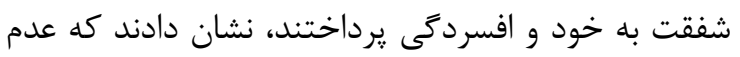

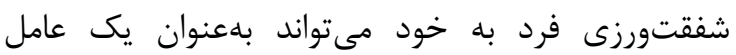

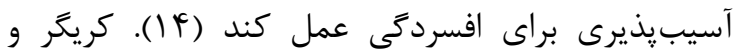

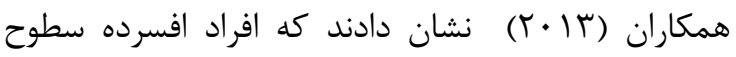

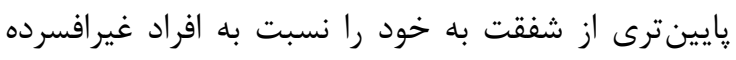

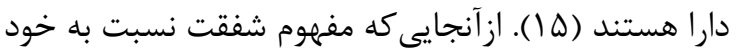
در يك دهه كذشته وارد ادبيات يزوهشى روانشناسى شده

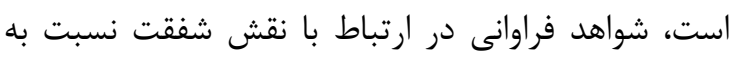
خود بر سلامت روان و مشكلات روانشناختى وجود ندارد،

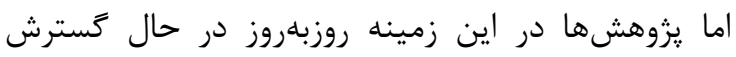
ازاينرو با توجه به مطالب ذكرشده مىتوان بيان نمود بيماران مبتلابه سرطان يستان به دليل ماهيت بيمارى و

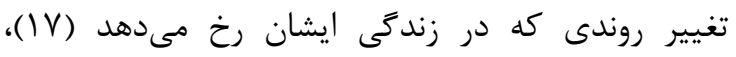

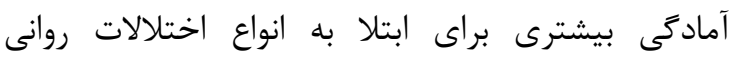

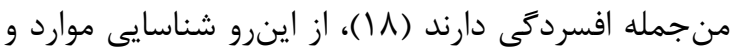

افسردگى يك يريشانى روانى رايج در بين اكثر بيماران

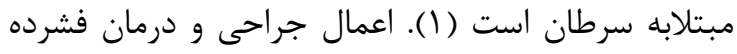

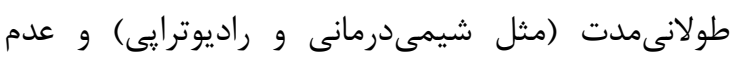
قطعيت در طول ييشرفت بيمارى مىتواند منجر به علايمى مثل اضطراب، ترس و افسردگى شود (T).

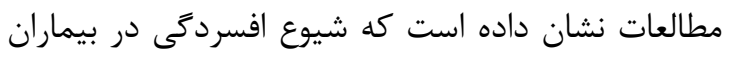

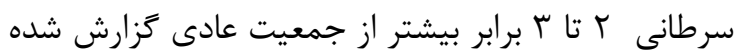
است (ז). بر اين اساس •هـ/ از مبتلايان به سرطان ريه،

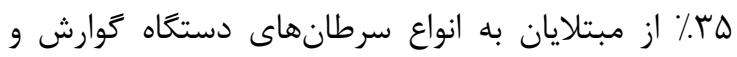

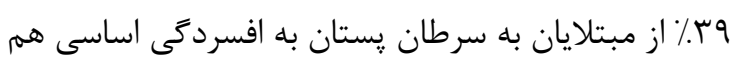

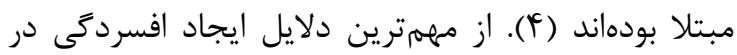

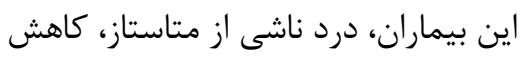

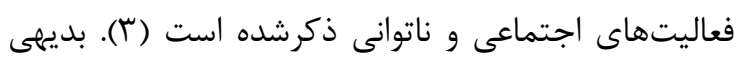
است زمانى كه ابتلاى فرد به سرطان تشخيص داده شود،

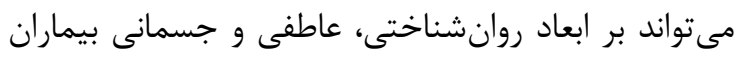

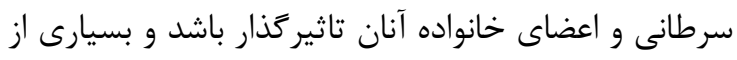

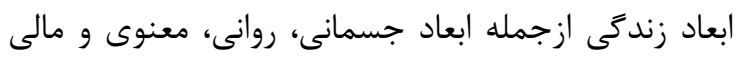
آنان را تغيير دهد و همجنين بر روابط اجتماعى آنان آنان

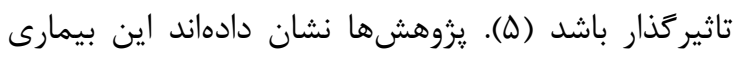

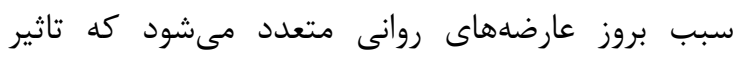

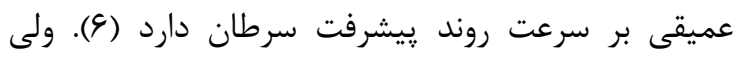

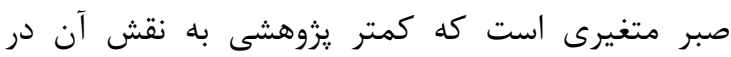

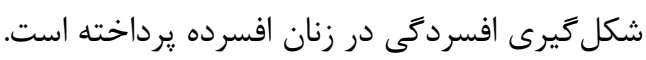

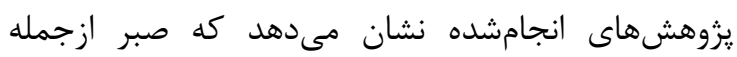
متغيرهايى است كه مىتواند در افزايش سلامت روان افراد

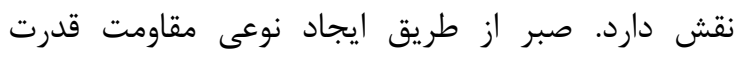

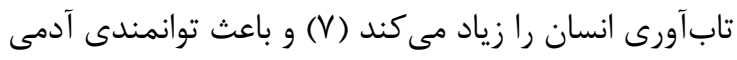

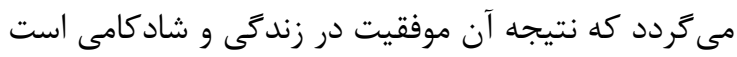

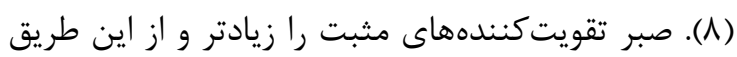

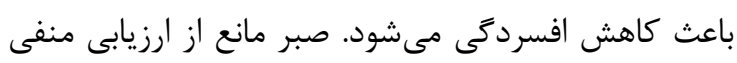

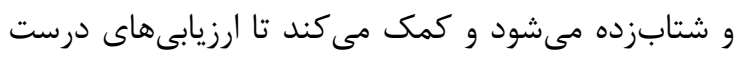

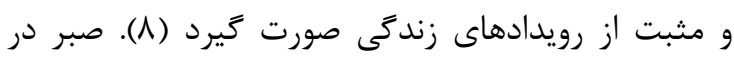

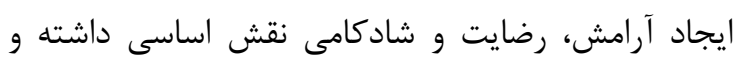
همجنين موجب تقويت ذهنيت مثبت انديشى و سلامت رإِ

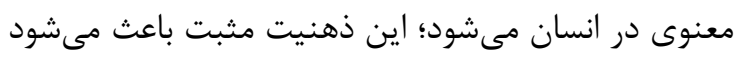

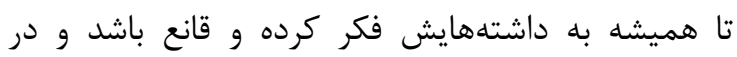

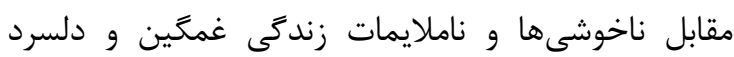


ركرسيون گام به كام جهت نشان دادن تعيين سهم

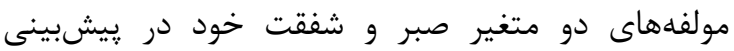
افسردگى مورد استفاده قرار ترفت.

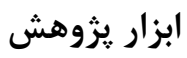

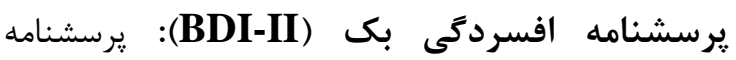

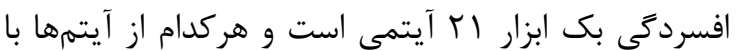
يك نشانه افسردىى مرتبط است. در اين يرسشنامه به هر

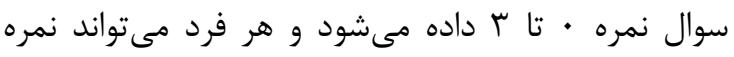

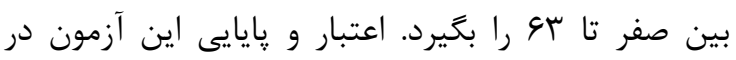

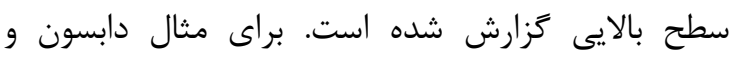

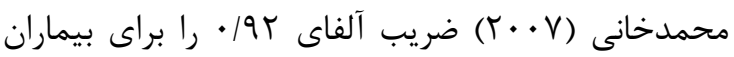

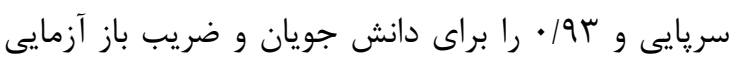

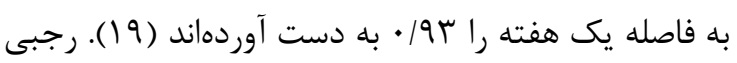

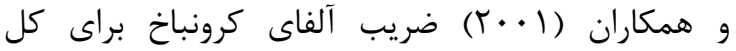

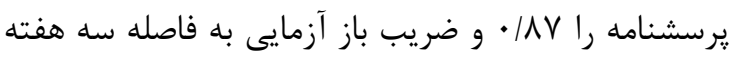

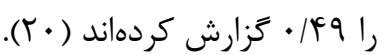

يرسشنامه شفقت به خود نف (r+.r): يرسشنامه شفقت به خود، شامل צr ماده است و ياسخها در آن در

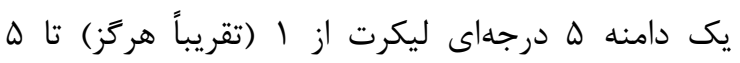

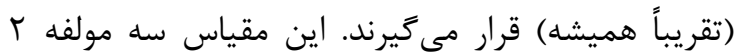
قطبى را در قالب 9 زير مقياس مهربانى با خود، قضاوت

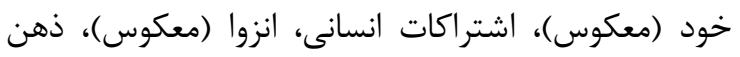

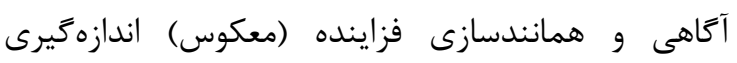

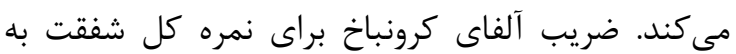

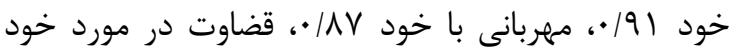

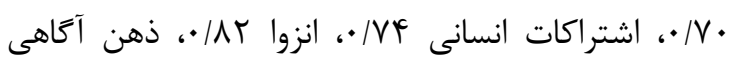
IVD

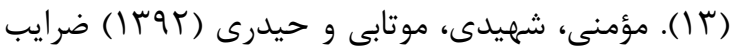

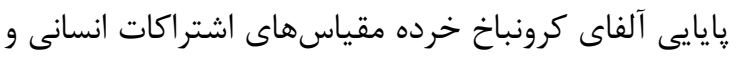

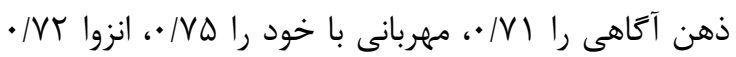

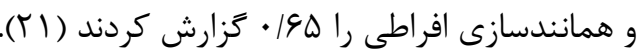

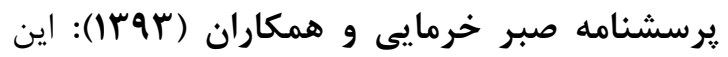

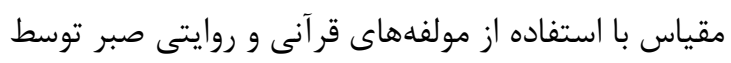

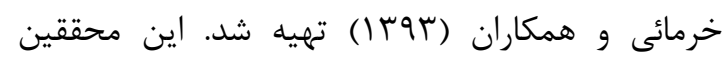
بامنظور ساخت اين مقياس در ابتدا، كليه آيات مرتبط با

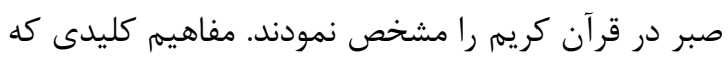
كليه آيات مرتبط با صبر بر آن تاكيد دارند ران راستخر استراج كردند. سيس از اين مفاهيم كليدى براى تدوين عباراتى

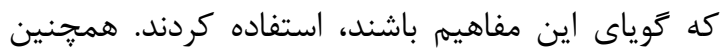

متغيرهايى كه زمينه بروز يا بيشگيرى افسردكى را فراهم

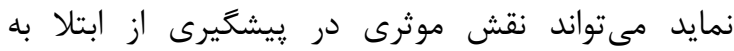

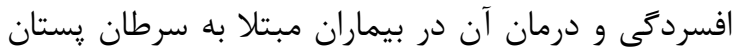

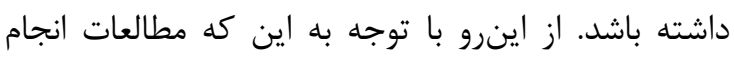
شده كمتر به بررسى رابطه صبر و شفقت خود با افسردكى بانى

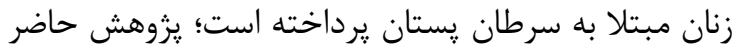

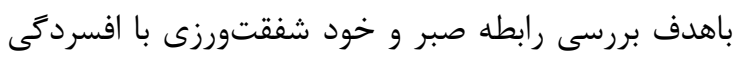

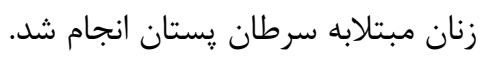

\section{مواد و روشها}

يزوهش حاضر با روش مقطعى انجام گرفت كه جامعه آن

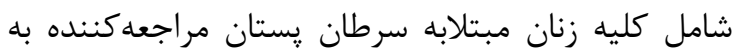
بخش شيمىدرمانى و انكولوزى مركز يزشكى مهديه،

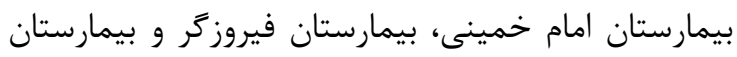

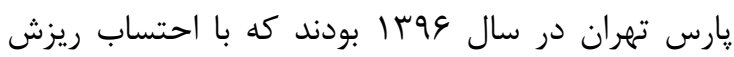

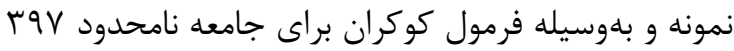

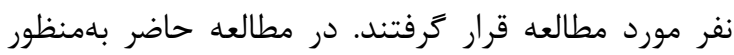
نمونه كيرى از روش نمونههاى در دسترس استفاده شد. از واحدهاى :زوهش جهت شركت در مطالعه رضايتنامه

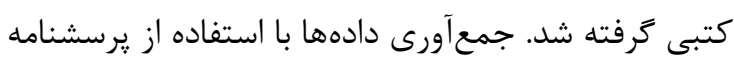

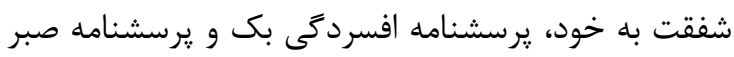

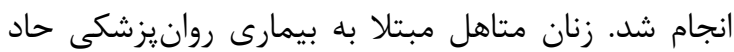
كه از طريق ارزيابى و مصاحبه بالينى توسط روانشناس ناس منان

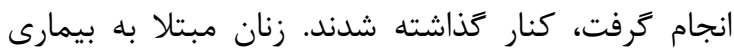

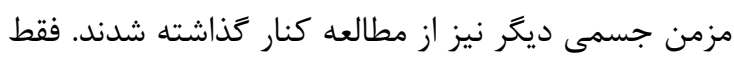

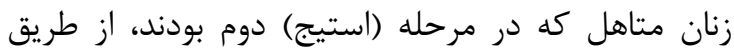
مشاهده يروندها و با تشخيص يزشك معالجشان انتخاب

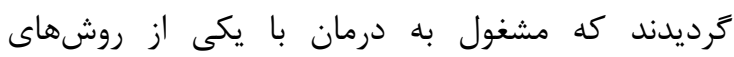

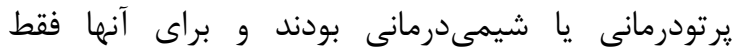
تشخيص سرطان يستان كذاشته شده بود و فاقد عود مكرر

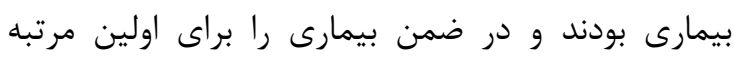

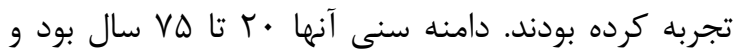
حداقل سواد خواندن و نوشتن داشتن و تمايل به همكارى داى دانه و شركت در يزوهش راد داشت دان.

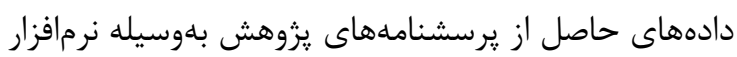

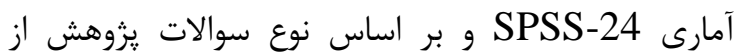
ضريب همبستخى ييرسون و ركرسيون جند إنانه استفاده

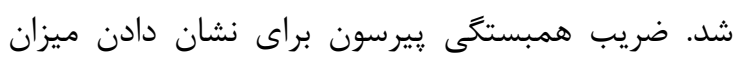

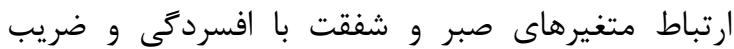


ضريب همبستخى يِرسون متغيرهاى يزوهش آورده شده

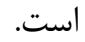
همانطور كه در جدول شماره r مشاهده مىشود ميانكين

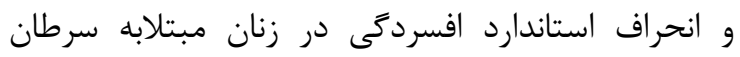
يستان N/VA

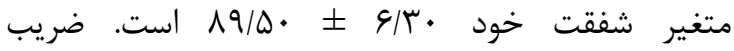

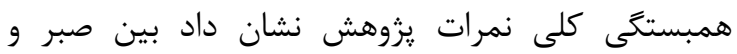

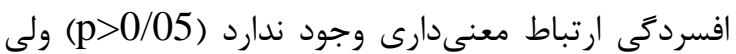

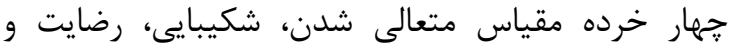

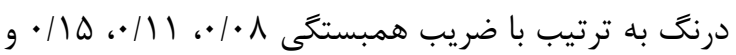

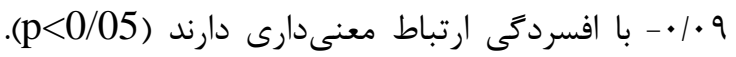
همجنين يافتههاى يزوهش نشان داد بين شفقت به خود و

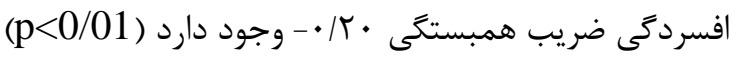
و از بين خرده مقياسهاى شفقت، مهربانى به خود آساء.،

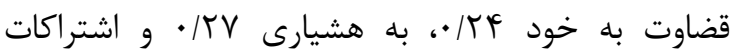
انسانى FF/F/•- به خود رابطه معنىدارى داشته است

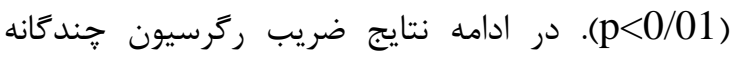
Fامبه كام، جهت تعيين ميزان سهم متغيرهاى شفقت به درائ

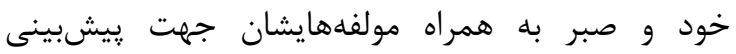

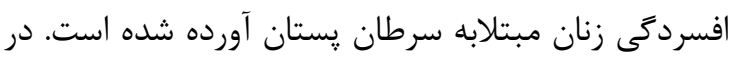

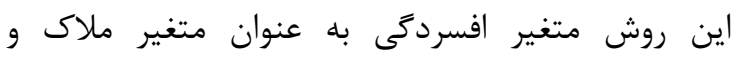
مولفههاى صبر و شفقت به عنوان متغير ويشبين إنين وارد

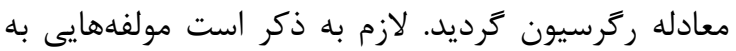

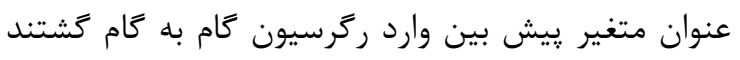

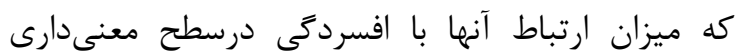
(p<0/05)

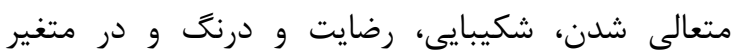

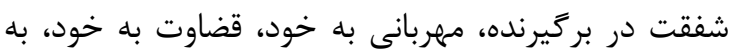
هشيارى و اشتراكات انسانى بود.
مفاهيمى كه با يكديگر مشابهت داشتند را حذف نموده و

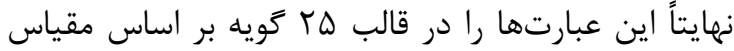

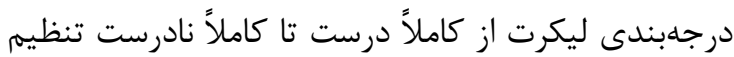
كردند و ويزَّىهاى روانسنجى آن را بر روى دانشجويان

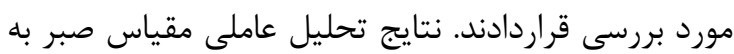
روش مولفههاى اصلى همراه با ترخش واريماكس نشاندهنده وجود ه مولفه صبر بود كه به ترتيب متعالى

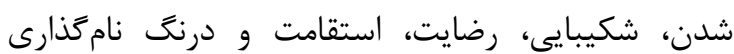
شدند. همجنين نتايج همسانى درونى شواهدى مبنى بر روايى همخرا و افتراقى مقياس صبر فراهم نمود. بلمنظور

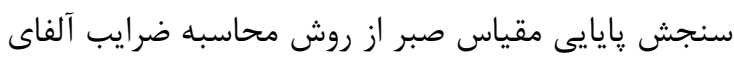

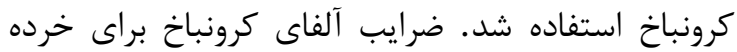

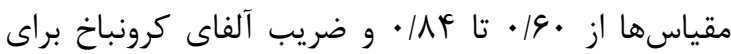

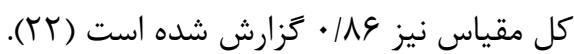

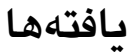

در يزوهش حاضر، پِ از جمعآورى دادهها، براى تجزيه تحليل اطلاعات از آمار توصيفى و استنباطى استفاده شد.

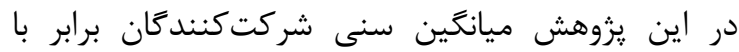

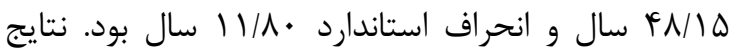
جدول شماره 1 نشان مى دهد كه از بين اعضاى نمونه

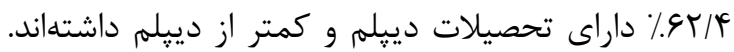

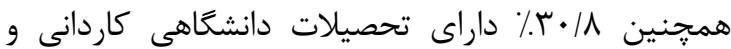

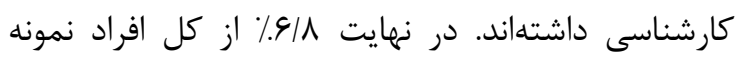

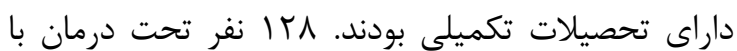

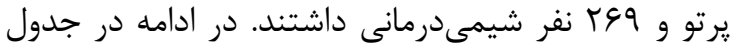

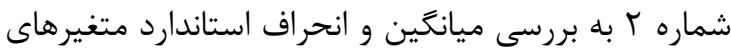
افسردىى، صبر و شفقت به همراه مولفههايشان به همراه

جدول ا: خصوصيات جمعيت شناختى افراد شركت كننده در يزوهش

\begin{tabular}{|c|c|c|c|}
\hline درصد فراوانى & فراوانى & & \\
\hline$G Y / F$ & rFG & دييلم و كمتر از دييلم & \\
\hline$r \cdot / \Lambda$ & ITr & كاردانى و كارشناسى & تحصيلات \\
\hline $9 / 1$ & rq & تكميلى & \\
\hline$r V / V$ & 11. & 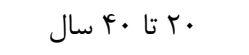 & سن \\
\hline$\Delta \mathrm{V} / \cdot$ & TTV & أ تا •ع سال & \\
\hline $1 \omega / \Gamma$ & 4. & اء سال و بالاتر & \\
\hline$Q V / V D$ & r\&q & شيمى درمانى & روش درمان \\
\hline re/ra & IrA & يرتودرمانى & \\
\hline
\end{tabular}




\begin{tabular}{|c|c|c|c|c|c|}
\hline ضر با مولفههاى شمبستى صبر & ضفت با مولفه همبستى صبى & ضريب همبستخى متين بـ افسردى هاى & 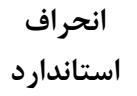 & ميانغين & \\
\hline-- & -- & $1 / \cdot$ & $\Lambda / \vee \wedge$ & $r 9 / 9 r$ & افسردگى \\
\hline-- & $\cdot / \cdot r$ & $\cdot 1 \cdot \Lambda^{*}$ & r/l & $r V / q V$ & متعالى شدن \\
\hline-- & $\cdot / \cdot \wedge$ & $\cdot 111^{*}$ & r/MF & $r F / q$. & شكيبايى \\
\hline-- & $\cdot / 1 r^{* * * * \%}$ & $\cdot / 1 Q^{* * *}$ & $r / \cdot \Lambda$ & ID/AT & رضايت \\
\hline-- & $\cdot / \cdot r$ & $\cdot / \cdot 1$ & $1 / 99$ & ৭/^६ & استقامت \\
\hline-- & $-\cdot 1 \cdot 9^{*}$ & $-\cdot / \cdot 9^{*}$ & $1 / 49$ & $1 \cdot / 1 \mathrm{~V}$ & درنغ \\
\hline-- & $\cdot 111^{*}$ & $\cdot / \cdot V$ & $\varepsilon / \mu$. & $11 / 99$ & صبر \\
\hline$\cdot / r^{* * * *}$ & -- & $-\cdot|\Gamma|^{* * * *}$ & $\Gamma / \Lambda \cdot$ & $1 \cdot 19 \mathrm{~V}$ & مهربانى به خود \\
\hline$\cdot 111^{*}$ & -- & $\cdot / T Y^{* * *}$ & $T / V T$ & $10 / 91$ & قضاوت خود \\
\hline$\cdot / 1 \Gamma^{* * * *}$ & -- & $\cdot / T V^{* * * m}$ & r/l & $19 / 1$. & به هشيارى \\
\hline$\cdot / 1 r^{* * * * *}$ & -- & $\cdot / \cdot r$ &.$/ \cdot t$ & $\mid F / N T$ & همانندسازى افراطى \\
\hline$\cdot 11 \cdot *$ & -- & $-\cdot / \mu r^{* * * * *}$ & $r / 9 \Delta$ & $I F / V R$ & اشتراكات انسانى \\
\hline .1 .9 & -- & $-\cdot / \cdot V$ & $T / / \Delta$ & $14 / 4 q$ & انزوا \\
\hline.$/ 11^{*}$ & -- & $-\cdot / r \cdot{ }^{*}$ & $\varepsilon / \pi$. & $\Lambda 9 / \Delta$. & شفقت خود \\
\hline
\end{tabular}

$(p \leq 0 / 05 * \& P \leq 0 / 01 * *)$

اشتراكات انسانى و مهربانى به خود حدود ها ٪ از واريانس افسردكى را تبيين مى كنند. نتايج جدول شماره f نشان مىدهد كه از بين خرده مقياسهاى وارد شده در معادله رگرسيون گام به گَام دو

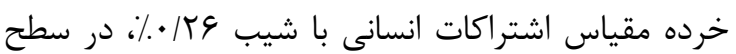

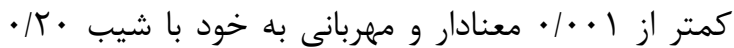

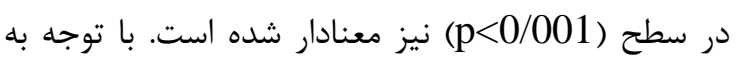
مقادير بتاى بهدستآمده مىتوان كفت كه مقادير بتا نشان مىدهد با افزايش يكى انحراف استاندارد در اشتراكات انسانى، افسردىى زنان مبتلا به سرطان زبستان به ميزان

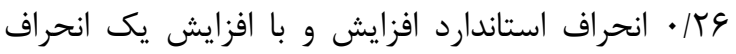

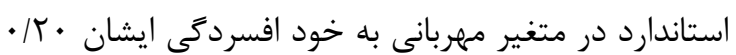
كاهش مىيابد. لذا با توجه به نتايج جداول فوق مى متوان به بيان نمود كه دو خرده مقياس اشتراكات انسانى و مهربانى به خود توانايى قيشبينى ميزان افسردگى زنان دود مبتلا به به

$$
\text { سرطان پستان را دارد. }
$$

نتايج جدول س نشان مىدهد كه در گام اول خرده مقياس اشتراكات انسانى به دليل دارا بودن بالاترين ضريب دهري همبستگى صفر مرتبه با متغير وابسته وارد معادله

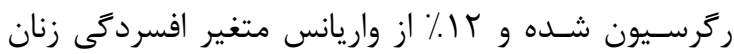
مبتلابه سرطان پستان را تبيين كرده است كه با توجه بـ وله F

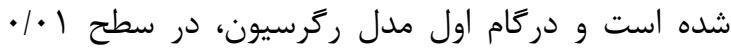

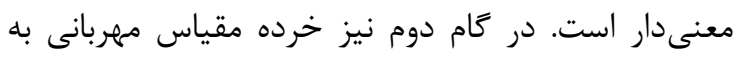

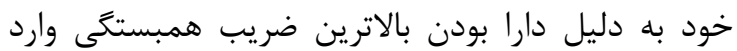
معادله شد و به همراه مولفه اشتراكات انسانى مجموعاً

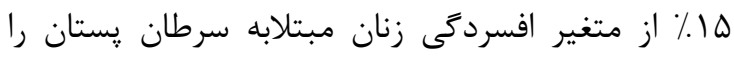

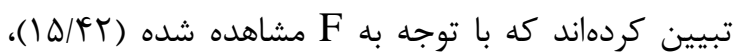

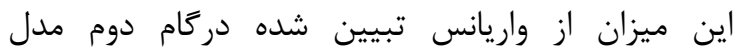
رگرسيون، در سطح I • • • معنىدار است. ازاينرو مىتوان بيان نمود از بين خرده مقياسهاى دربر صبر و شفقت دو مولفه

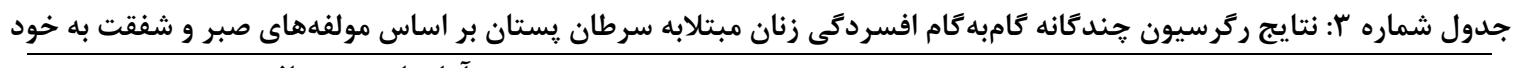
آمارهاى تغييريافته

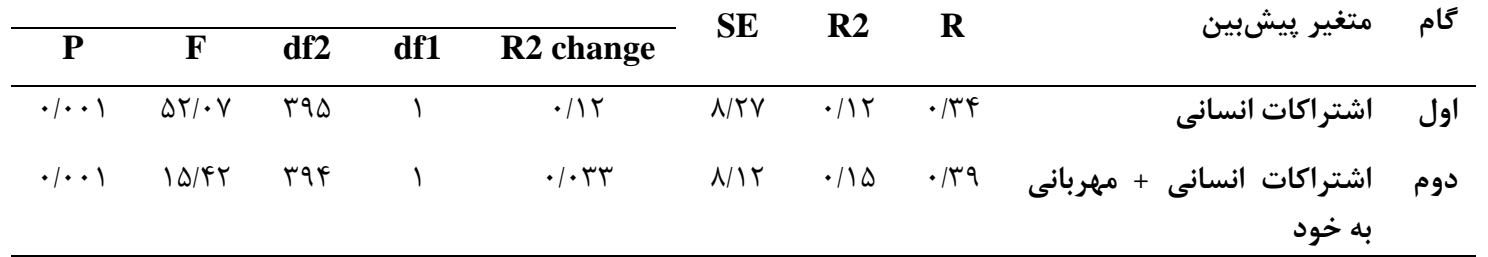




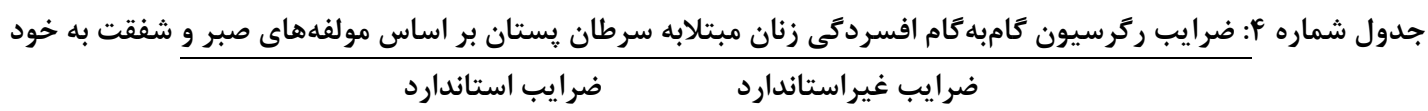

\begin{tabular}{|c|c|c|c|c|c|}
\hline $\mathbf{P}$ & $\mathbf{t}$ & B & SEB & B & متغير \\
\hline$\cdot 1 \cdot \cdot 1$ & $V / V V$ & & $r / \cdot \Delta$ & $r M / V I$ & مقدار ثابت \\
\hline$\cdot 1 \cdot \cdot 1$ & $\Delta / \cdot \mathcal{F}$ & $\cdot / 49$ & $\cdot / 1 \Delta T$ & $\cdot / \mathrm{VV}$ & اشتراكات انسانى \\
\hline$\cdot 1 \cdot \cdot 1$ & - & $-\cdot / T \cdot$ &.$/ 111$ & $-\cdot / 4 \varphi$ & مهربانى به خود \\
\hline
\end{tabular}

هيجانهاى منفى، آنها نيازمند تسكين دادن و رفع كردن

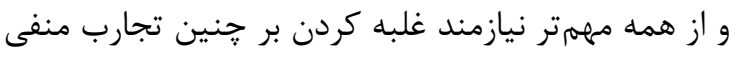
بدون هركونه آسيب هستند. اين افراد بايد شفقت نارنا

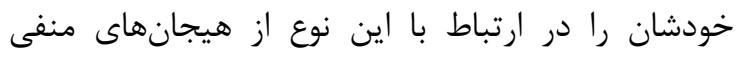

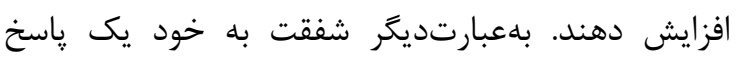
ممكن به رنج و شكست شخصى است و مى دواند

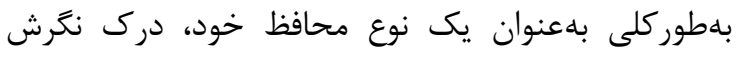

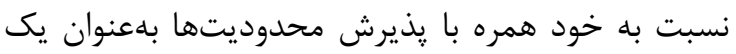
بخش طبيعى از تجربه انسانى تعريف شود (T/Y). همجنين

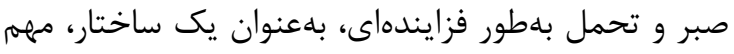

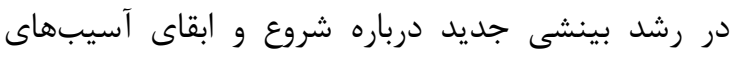
روانى و همجنين بيشخيرى و درمان مشاهده شده است.

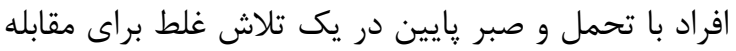

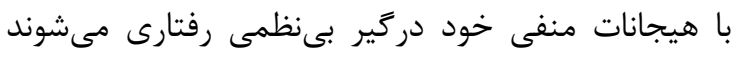
(TF) بيان نمود افراد مبتلا به سرطان علايم جسمانى و روانى زيادى را تجربه نموده، خود را در كنترل اين علايم ناتوان ديده و ناتوانى خود را به تعبير اشتباه با صبر يكى نمانى

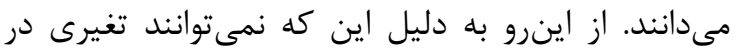

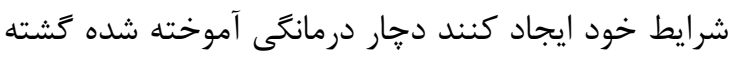
و افسردگى آنها بالا مىرود. از طرف ديخر در تبيين ارتباط مولفههاى صبر و شفقت با فارود

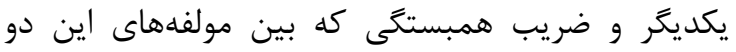

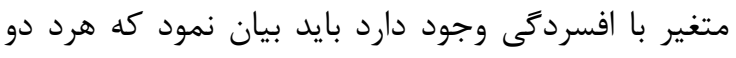
شفقت به خود و صبر، نيازمند تشخيص اين امر هستند كه انسانها موجودات كاملى نيستند و شرايط نيز هميشه براى افراد مناسب نيستند؛ همجنين اين باور وجود دارد

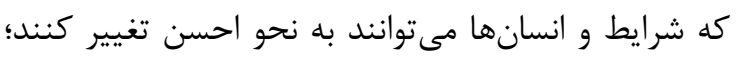
بنابراين شايسته يذيرش و درك هستند؛ لذا انتظار مىرود شفقت به خود بهطور معنى معنادارى با صبر و تحمل

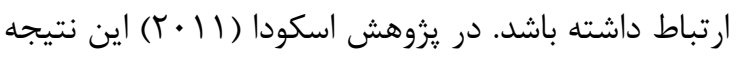

يزوهش حاضر باهدف تعيين ميزان سهم صبر و خود شفقتورزى در پيشبيشى افسردىى زنان مبتلا به سرطان

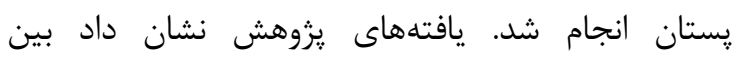
افسردگى و مولفههاى متعالى شدن، شكيبايى، رضايت و إنان

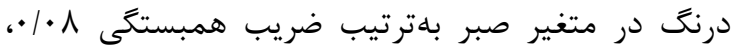

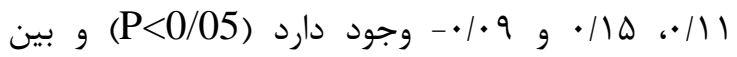
شفقت به خود و افسردكى ضريب همبستكى • آ/ •--وجود دارد ( p</01) و از بين خرده مقياسهاى شفقت،

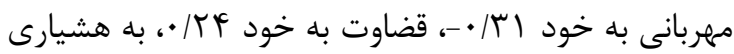

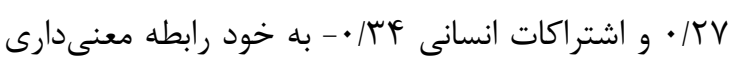

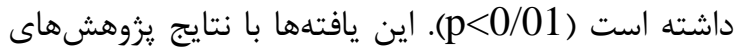

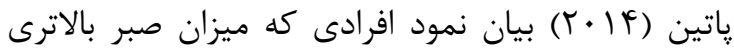

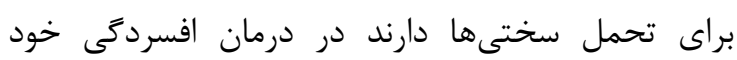
موفقتر از ديكران مىباشند (9) و يزوهش يرويز إداده ليلان دان

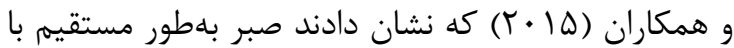

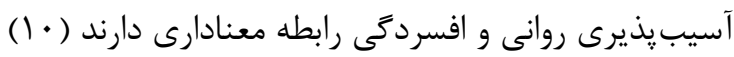

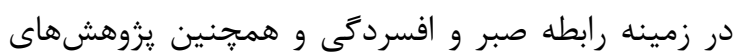

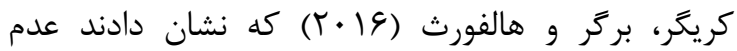

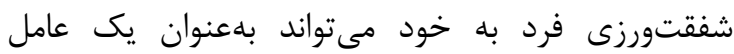

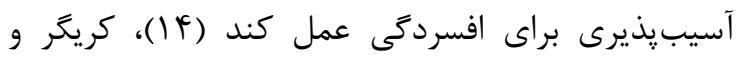

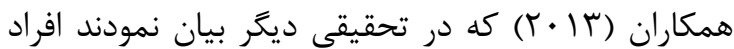

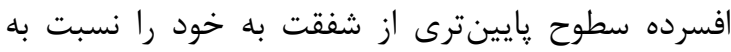

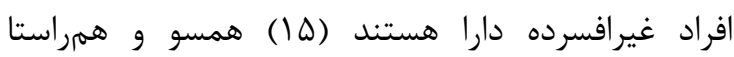

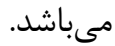
در تبيين يافتههاى حاضر بايد اذعان كرد افراد مبتلا به سرطان پستان هيجان منفى زيادى مثل غمه، ناراحتى،

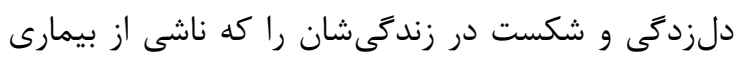
ايشان مىباشد تجربه مى كنند كه منجر به افزايش ميزان

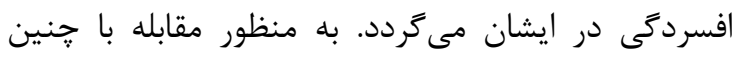


مبتلا به سرطان يستان يرداخته شود و در ثانى فنون

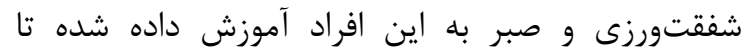
متعاقباً ميزان سلامت روان آنها نيز افزايش يابد.

\section{نتيجهكيرى}

با توجه به نتايج حاصل از يزوهش حاضر مى توان بيان نمود كه افسردگى با صبر و شفقت به خود در زنان مبتلا به سرطان پستان رابطه دارد و برخى از مولفههاى صبر و و

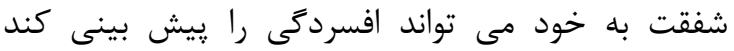
بنابراين ييشنهاد مى شود كه اين دو عامل در بررسى

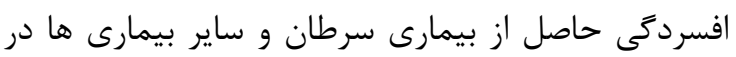

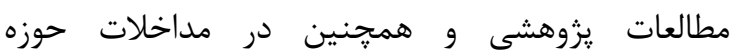
روانشناسى سلامت و مداخلات تخصصى يزشكى به جهت در نظر گرفتن تاثيرات متقابل جسم و روان بر روى هم و كمك به درمان سرطان با در نظر گرفتن مولفههاى روانشناختى دخيل در بيمارى سرطان مد نظر قرار گيرد.

\section{تقدير و تشكر}

يزوهش حاضر برگرفته از رساله دكترى تخصصى رشته روانشناسى مىباشد كه توسط نويسندگان حاضر با كد اخلاق D/71096 از دانشعاه ييام نور تهران اجرا گرديد.

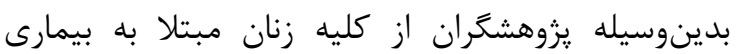
سرطان يستان و كادر درمانى مراكز يزشكى مهديه، بيمارستان امام خمينى، بيمارستان فيروزگر و بيمارستان يارس تهران كه به همراهى و همكارى خود انجام اين يزوهش را ميسر نمودند نهايت تشكر و قدردانى را ابراز

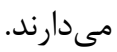

\section{References}

1. Stewart B, Wild CP. World cancer report 2014. Health 2017.

2. Dedelio, Fadiloglu Ç, Rüçhan U. A survey of functional living and social support in patients with cancer. Turkish Journal of Oncology 2008; 23(3): 132-9.

3. Farokhzad P, Jannesaran M, Norouzi A , Arabloo J. Effect of Emotional Catharsis by Writing on Depression in female
حاصل كرديد كه شفقت به خود بهطور معنىدارى با بخشايشكرى همبستكى دارد و افرادى كه از ميزان شفقت به خود بالايى برخوردارند مىتوانند در برابر رفتارهاى

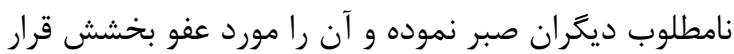

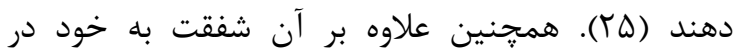

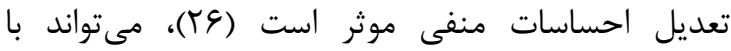
احساس صبر بيشتر نسبت ديكران و در نتيجه احساس

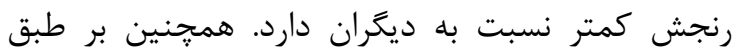

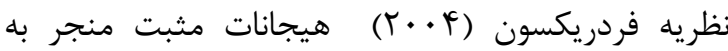
كسترش توجه و تفكر، كاهش برانگيختخى حاصل از

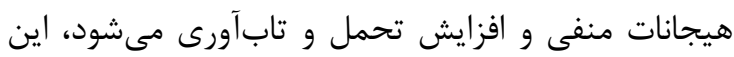

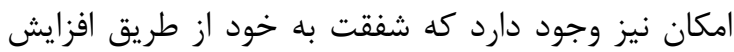
هيجانات مثبت تحمل و صبر را در زنان داراى سرطان

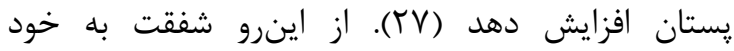
مىتوانند تبيين كننده تغييرات افراد در ميزان صبر و وردان بردبارى افراد تلقى كردد. همجنين شفقت به خود از طريق تيق ايجاد مراقبت، توجه جديد به خود و ييشنهاد فرايندهاى درونى دلسوزانه به تغيير افراد كمك مى كند. اين تغييرات

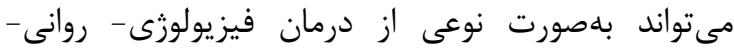

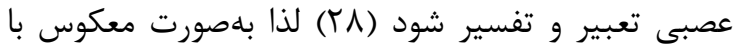
افسردىى افراد رابطه دارد. در محدوديتهاى يزوهش حاضر بايد بيان نمود با توجه به إنه

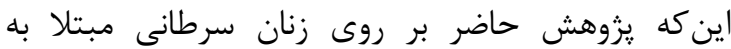

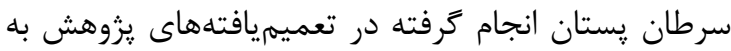

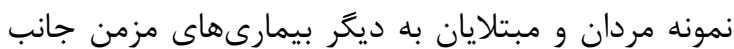
احتياط رعايت شود؛ افسردىى مى تواند با متغيرهاى زيادى در ارتباط باشد كه در يزوهش حاضر تنها به شفقت و صبر

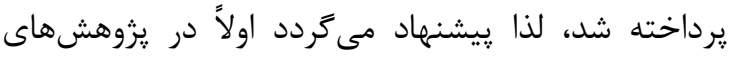
ديكر به بررسى متغيرهاى همبسته ديخر با افسردكى زنان

Cancer Patients. Razi Journal of Medical Sciences 2017; 24(1): 71-64.

4. Antoni MH, Lehman JM, Kilbourn KM, Boyers AE, Culver JL, Alferi SM, et al. Cognitive-behavioral stress management intervention decreases the prevalence of depression and enhances benefit finding among women under treatment for earlystage breast cancer. Health Psychology 2001; 20(1): 20. 
5. Schmer CE. The effect of a cancer diagnosis on hope and resilience: a correlational, longitudinal study: University of Missouri-Kansas City. 2010.

6. Pilarski DJ. The Experience of younger women diagnosed with breast cancer involved in dance/movement therapy with regards to body image and sexuality. 2009.

7. Razavidoost G ,Khakpour H, Fanodi S, Okati M. The role of patience in the serenity and spiritual health from Quran and Islamic traditions of view. Medical History Journal 2016;7(25):60-129.

8. Faribors B, Fatemeh A, Hamidreza H. The relationship between nurses' spiritual intelligence and happiness in Iran. Procedia-Social and Behavioral Sciences 2010; 15(56):5-61.

9. Patten SB. Support, patience, and expectancy: therapeutic options alongside intensified treatments for depression? : SAGE Publications Sage CA: Los Angele, CA 2014.

10. Leilan MP, Kheiri Y, Babapour J. Relationship between Attachment to God and Trust with Psychological Vulnerability of Students with Mediating on Patience. International Research Journal of Applied and Basic Sciences 2015; 9(9):73-1568.

11. Trompetter HR, de Kleine E, Bohlmeijer ET. Why does positive mental health buffer against psychopathology? An exploratory study on self-compassion as a resilience mechanism and adaptive emotion regulation strategy. Cognitive therapy and research 2017; 3(41): 68-459.

12. Neff KD, Germer CK. A pilot study and randomized controlled trial of the mindful self compassion program. Journal of clinical psychology 2013; 69(1):28-44.

13. Hupfeld J, Ruffieux N. Validierung einer deutschen version der SelfCompassion Scale (SCS-D). Zeitschrift für klinische Psychologie und Psychotherapie 2011.

14. Krieger T, Berger T, Grosse Holtforth M. The relationship of self-compassion and depression: Cross-lagged panel analyses in depressed patients after outpatient therapy. Journal of affective disorders 2016; 39: 45-202.
15. Krieger $\mathrm{T}$, Altenstein $\mathrm{D}$, Baettig I, Doerig N, Holtforth MG. Self-compassion in depression: Associations with depressive symptoms, rumination, and avoidance in depressed outpatients. Behavior therapy 2013; 44(3):13-501.

16. MClinPsych E-JM, DClinPsych RNB. The relationships between psychological flexibility, self- compassion, and emotional well- being. Journal of Cognitive Psychotherapy 2016; 30(1):60.

17. Jensen LS, Overgaard C, Bøggild H, Garne JP, Lund T, Overvad K, et al. The long-term financial consequences of breast cancer: a Danish registry- based cohort study. BMC public health 2017;17(1):853.

18. Ho S-Y, Rohan KJ, Parent J, Tager FA, McKinley PS. A longitudinal study of depression, fatigue, and sleep disturbances as a symptom cluster in women with breast cancer. Journal of pain and symptom management 2015; 49(4):15-707.

19. Dabson E, Mohammadhkani P. Psychometric features of depression inventory-II in depressive disorders in partial remission. J Rehab 2007; 80:6-8.

20. Rajabi G, Attari Y, Haghighi J. Factor analysis of Beck Depression Inventory items among the students of Shaheed Chamran University (Ahwaz). J Edu Psychol 2001; 3:49-66.

21. Momenif, Shahidi S, Mootabi F, Heydari M. Psychometric properties of a Farsi version of the Self-Compassion Scale (SCS) 2014.

22. Khormaee F, Farmani A, Soltani E. The Patience Scale: Instrument development and estimates of psychometric properties. Journal of Educational Measurement. 2015;5(17):83-99.

23. Neff KD, Dahm KA. Self-compassion: What it is, what it does, and how it relates to mindfulness. Handbook of mindfulness and self-regulation 2015; 37-121.

24. Leamy M, Bird V, Le Boutillier C, Williams J, Slade M. Conceptual framework for personal recovery in mental health: systematic review and narrative synthesis. The British Journal of Psychiatry 2011;199(6): 52-445. 
25. Skoda AM. The relation between selfcompassion, depression, and forgiveness of others: University of Dayton 2011.

26. Finlay-Jones AL, Rees CS, Kane RT. Self-compassion, emotion regulation and stress among Australian psychologists: Testing an emotion regulation model of self-compassion using structural equation modeling. PloS one 2015; 10(7):e0133481.

27. Fredrickson BL. The broaden-and-build theory of positive emotions. Philosophical
Transactions of the Royal Society B: Biological Sciences 2004; 359 (1449): 1367.

28. Gilbert P, Procter S. Compassionate mind training for people with high shame and self-criticism: Overview and pilot study of a group therapy approach. Clinical Psychology \& Psychotherapy 2006; 13(6): 79-353. 